\title{
THE SANITARY ADMINISTRATION OF THE PORT OF BOMBAY.*
}

\author{
BY JOHN CRIMMIN, V.C., C.I.E., I.M.S., AND P. TARGETT ADAMS,
} D.P.H.

The City of Bombay is situated upon an island, which is connected by railway embankments and bridges on the north with the larger island of Salsette and the mainland. Bombay island consists of a low-lying plain about eleven miles long north and south, and three miles across, flanked by two parallel ridges of low hills.

Colaba, the headland formed by the eastern ridge, protects the southern part of the harbour. The western ridge terminates in Malabar Hill, 180 feet high, and between these hills lies a shallow, sandy and rocky bay, unnavigable, and known as the Back Bay. The northern portion of the island of Colaba contains docks, together with crowded and insanitary back-streets, and in the more open parts barracks and industrial buildings.

Bombay Harbour is fifteen miles long, N.N.E. by S.S.W., and four to six miles wide, with average depths of 4 to 6 fathoms, the bottom consisting chiefly of mud. The harbour contains several islands, rocks and shoals, and its shores are indented by numerous bays and inlets.

Port Limits.-The southern port limit extends from Kundari Island to abreast the mainland. The western port limit is from Kundari Island to the outer lighthouse, and thence to Malabar Point. The northern boundary is from Hog Island to Trombay Light; and the eastern port limit from Nocar Point across the entrance of the Pen River to the south extreme of Karanja Island.

Docking Accommodation :-

Prince's Dock, to take ships 440 feet long, drawing 23 feet 10 inches of water.

Victoria Dock, to take ships 429 feet long, drawing 19 feet 6 inches of water.

Bombay (Admiralty) Doek, to take ships 300 feet long, drawing 14 feet 6 inches of water.

Duncan Dock, to take ships 259 feet long, drawing 17 feet 10 inches of water.

P. and 0 . and Ritchies' Dock, to take ships 306 feet long, drawing 18 feet 6 inches of water.

* Read before the Metropolitan Branch of the Incorporated Society of Medical Officers of Health, May, 1901. 
B.I. (Lower Mogul) Dock, to take ships 217 feet long, drawing 14 feet of water.

B.I. (Upper Mogul) Dock, to take ships 196 feet long, drawing 14 feet of water.

Merewether (Princes Dock), to take ships 555 feet long.

The Anchorage is usually along the western side of the harbour, abreast of the town, but there is a good "holding-ground "throughout the harbour. The quarantine anchorage is to the eastward of the middle-ground island.

The Population of Bombay varies, but is roughly about 901,650 , composed of Europeans, Eurasians, Parsees, Persians, Arabs, Sidies, Mahrattas, Camatees, Indo-Portuguese, and a great number of sailors of all nations.

Water-Supply of City and Shipping.-This is chiefly derived from the public supply, which is laid on throughout the docks. Some of the native craft derive water from other sources, such as wells, but these are few in the neighbourhood of the docks.

Imports.-Piece goods, iron, machinery, crockery-ware, liquors, copper, brass, coals, wood, and kerosene-oil.

Exports.-Paw cotton, twist yarns, dyeing materials, grain, resins, hides, opinm, tobacco, flour, seeds, oil, spices, horns, and wool.

The docks are administered by "The Port Trust," are admirably equipped and well managed. The buildings are mostly new, with the latest and most approved hydraulic machinery, and probably as free from rats as docks could well be. Rat-catchers are constantly employed.

\section{The Port Santtary Administration of Bombay.}

Twelve years before plague invaded the City of Bombay an efficient system of port sanitary administration was organized by Lieutenant-Colonel MacCartie, C.I.E., I.M.S., and subsequently much improved by him and his coadjutor, Major Crimmin, V.C. (now the Port Health Officer of Bombay).

In the Presideney and the immediate neighbourhood of the eity there has been a most virulent epidemic of plague since 1896, in addition to smaller epidemies of variola, cholera, measles, relapsing fever, etc. In Bombay exist all the factors for the spread of infections diseases far and wide to the numerous ports with which this town is daily brought into contact by means of its shipping. Many of these places afford such favourable local receptive conditions, that had plague been exported to them it would most probably have assumed epidemic proportions. This would no doubt have happened had 
the port sanitary authorities of Bombay exercised less care and vigilance.

In a Bombay Government Resolution (No. $7416 \mathrm{P}$., dated October 25th, 1899) the following paragraphs occur:

"The sea medical inspection was, from the importance and magnitude of the interests involved by the spread of plague out of India, a source of the greatest anxiety to Government.

"But events have proved that no department of plague administration has been better managed. The thoroughness and successful conduct of the operations as a whole has commanded the warm admiration of Government, while the efforts of each individual connected with the inspections deserve the highest praise.

"Nothing but a magnificent devotion to duty could have sustained them in the performance of work which was as responsible as it was monotonous, irksome, and often disgusting.

"The spirit of cordial sympathy and courtesy that pervaded all ranks of the various staffs has been keenly appreciated by Government."

But few cases can be reasonably said to have been even indirectly exported through ships arriving from, or infected in Bombay, to which bills of health were granted by us.

Before plague becomes established as an epidemic within an uninfected area, much must depend upon many local factors, such as density of population and buildings, insanitary conditions, etc., but probably on

(1) The quantity of infective material introduced, together with the frequency of its introduction, its vitality and virulence, as influenced by the means of transport from the infected area to the uninfected area, and its mode of introduction. These considerations are of great importance in marine hygiene. For example, if the infective material be conveyed in a lascar's clothing, many circumstances will come into play to destroy or preserve the infectivity of those elothes, such as their exposure to air, sunlight, moisture, warmth, etc., or the contrary. In the persons of the passengers themselves, if the voyage be short, those on board may complete (and they do sometimes complete) their incubation period after leaving the ship, and thus carry the most active infection with them ashore, after having contracted the disease before embarkation. An infected rat may convey the infection, infecting by fleas or otherwise the shore rats.

(2) Connected with the suitability of the immediate environment of the unaffected area into which the infective material is introduced, many factors may come into force, such as the habits of the 
people; the sanitary conditions of their surroundings, meteorological causes, animals, and so forth, and thus increase the risks of an epidemic outburst.

These factors are important in the consideration of the risks of the exportation of plague by ships (as likewise they necessarily must be in any other case).

As we have already attempted to explain elsewhere, the biological and morphological characteristics of the plague bacillus are such that the altered conditions obtaining on board ship may, by reason of the length of the voyage, or the bringing into such a comparatively speaking small area of a number of infected rats, etc., affect favourably or unfavourably the virulence and vitality of the bacillus itself, and make its transport during a long ocean voyage difficult or the contrary. Tenacious of life as the infective material of plague appears to be when established in a suitable environment, its transmission from individual to individual is not readily established amongst Europeans in India, save in the pneumonic form of the disease, and then it occurs readily, especially if superadded to suitable insanitary surroundings.

In point of fact the transmission of plague appears to be chiefly, if not entirely, conveyed by means of direct inoculation, not excepting the so-called pneumonic type. It naturally follows that, provided the soil is suitable and the bacillus vital, the larger the quantity of infective material introduced into an uninfected area, the greater the risks of epidemicity. The greater the number of unrecognised cases of plague escaping from a port, or completing their incubation period after leaving the port, the greater the risks of the successful implantation of the disease in an epidemic form elsewhere, the opportunities afforded the bacillus of finding a suitable nidus to multiply upon being, of course, proportionally increased, because the chances of the total destruction of the bacillus are lessened.

Apart from the above considerations, there are many other circumstances which materially increase, alter, and modify the risks of the propagation of infectious diseases amongst Oriental peoples which have to be reckoned with in port sanitary control (in such places as Bombay)-i.e., religion, caste, prejudices, habits and customs, and often that most diffieult trait which our American friends so aptly term "sheer enssedness," such, for example, as the surreptitious passing of infected articles of clothing, etc., from the shore to the ship after the disinfection of all on board has been completed, and just prior to the vessel "getting under way." Special police supervision and regulation have to be organized to 
meet these contingencies by the port health officer, yet these factors all materially increase and complicate his task.

The port of Bombay, prior to the ratification of the Venice Sanitary Convention, was partly regulated by the terms of the Dresden Convention of 1893 (with reference to cholera, etc.), and since March 19th, 1897, by the Venice Convention, and we think we are justified in saying that in no port throughout the world has that Convention received greater attention and practical demonstration both with regard to its perfections and imperfections than at Bombay.

In point of fact, Bombay may be said to have been the practical workshop of these regulations, and although, as we have already said, most of the enactments of this Convention were already in force in Bombay before 1897, yet modifications necessarily arose in order to meet the exact letter of these international regulations, which should at the same time protect and facilitate the commerce of this and other nations if attacked by plague.

It is an axiom in port sanitary control that the most efficient administration is that which, whilst preventing the exportation or importation of infectious disease, at the same time affords the least possible interference and obstruction to the trade of those countries to and from which shipping and trade passes.

The ineffectual and unnecessary interference which any system of quarantine involves with the personal liberty and trade of the country in which it is enforced, without affording as great a protection as can be gained by other means, has always to be borne in mind. Although circumstances would at first sight appear to favour such a form of sanitary control in India, yet in practice it has proved (even there) that the system of quarantine will fail, unless it is absolute, and therefore almost impracticable in the present day. Why place a ship in a quarantine station when loopholes for evasion are many amidst a large native population, with native shipping continually affording means for intercommunication to take place between the ships and the infected population, or the reverse, as the case may be?

Its impracticability is only exceeded by its inutility, annoyance, and oftentimes actual cruelty, when one is alive to all the circumstances under which the poorer classes of people have to travel by sea-i.e., mostly huddled together, with all their bedding and belongings, on deck or below.

It is extremely difficult to carry out our English principles of sanitary control (with the avoidance of quarantine) amongst Eastern and Oriental peoples, and in countries containing a 
different internal sanitary machinery from that which can be adopted at home, and likewise amongst people whose religions (and they are numerous) and whose prejudices and customs are so diametrically opposed to any form of hygienic control whatsoever. Measures of actual personal detention by force, such as the strictest quarantine with military cordons, would, if properly carried out, most certainly produce serious disturbance amongst the natives, and probably prove abortive in the end by reason of the secretion of some article of infected clothing and its subsequent conveyance ashore.

Experience has proved without a doubt that a careful and thorough medical inspection, combined with disinfection of all the belongings of passengers and erew, together with their quarters aboard ship, the immediate isolation of infected persons, together with "segregation" of "contacts" and detention of "suspects" (in suitable encampments) during the usual period of the incubation of the disease for which he or she is segregated, is the most practicable method for the prevention of the propagation of infectious diseases here as elsewhere.

To these measures must be superadded the numerous sanitary regulations for the control of the ship-owners, captains, officers, European crew, and crews of native crafts. Stringent as many of these provisions are, yet it is not on actual legislative measures that success will depend, but rather on the exercise of tact, combined with constant supervision, persuasion, and judiciously-applied but firm police control. This has been our experience.

These are some of the principles upon which the sanitary administration of Bombay has been founded. With the result that, although the city can hardly be said to have been free of plague in its most severe and epidemic form since the inception of the disease, during the year 1896, and although, from April, 1897, to May, 1899 (two years), 179,859 craft, together with $3,131,049$ passengers and crew, passed through our hands, whilst at least 409 cases of plague were discovered, only 7 ocean-going steamers were reported to have had cases of plague on board which could with any valid show of reason be attributed to the embarkation of infected persons or kit at Bombay.

In January, 1897, it became apparent that the people were fleeing from Bombay by all the available routes, and were spreading the plague to inland towns, more especially to those near the eity, as well as to ports in the Bombay Presidency. It was, therefore, absolutely necessary to thoroughly and systematically examine all passengers and crews leaving the port of Bombay, and 
all vessels and native craft leaving for any place viâ the Bombay harbour.

To effect this, rules were promulgated under the Epidemic Diseases Act of 1897 (India), which precluded the delivery of a "port clearance" (and therefore a prohibition against sailing) to any vessel without the production of the port health officer's bill of health, certifying that the master or person in charge, officers, crew, and passengers (if any) of such vessel were free from any dangerous epidemic disease.

The main provisions of these rules are as follow:

1. All passengers leaving Bombay by sea for any port are medically examined on shore prior to embarkation.

2. All members of the crew of any vessel leaving Bombay for a port out of India are examined on shore before going on board such vessel, and the clothing and bedding of Asiatic (with the exception of Japanese) and African members of the crew disinfected.

Crews of vessels calling at Bombay and bound from an Indian port to another may be examined on board, provided that every member of the crew and passengers who joins at Bombay has been examined on shore before embarkation.

3. Places upon shore have been arranged for the examination of crews and passengers, and the officers of the port health staff receive daily intimation of the times and places at which examinations are conducted.

4. All passengers, when examined for vessels in the stream, and all those examined at the disinfeeting-sheds, whether intending to embark in the stream or the docks, are provided with stamped passes, which state that the passengers will not be permitted to embark unless the pass is produced and given up to the police officer stationed at the gangway of the vessel.

5. At the examination in the disinfecting-sheds native deck passengers, after disinfection of their baggage, and after they personally have been subjected to careful medical inspection, have their forearm stamped with a rubber stamp, bearing the date on which the examination takes place, so as to prevent the possibility of an unexamined passenger taking the place of one who has passed the examination.

6. When passengers are examined ashore for vessels in the stream, they are to be sent directly to the vessel in charge of one of the sanitary police. Under exceptional circumstances, and only when the procedure is absolutely necessary, a friend or attendant is allowed to accompany a passenger on board a vessel, but such friend or attendant must be medically examined by the inspecting 
officer, and must also be presented with a pass, stamped, dated, and signed by such inspecting officer, and endorsed with the word "Visitor."

7. Before commencing an examination, the senior inspecting officer present satisfies himself that all the subordinate officers, police inspectors, and police sepoys are at their posts; also that the correct date has been affixed to the rubber stamp for stamping the passes, etc.

8. The crew are examined and allowed on board before the examination of the passengers commences. The senior inspecting officer present obtains a "crew list" or a written statement of the crew from an officer of the ship, and sees that every member of the crew is examined, and that no person remains on board the vessel, concealed or otherwise, without being examined.

9. The medical officer present also sees that the boxes of the native crew, deck, and third-class passengers on vessels bound for ports out of India have been disinfected and stamped, and that the number of such boxes is not in excess of the number shown at the time of disinfection.

10. Should any member of the crew of any vessel be found to be suffering from or to present signs or symptoms suspicious of plague or other infectious disease, such person is prevented from embarking or re-embarking, and the bill of health is withheld until such person has been removed from such vessel, together with all his personal effects, and such parts of the vessel as were occupied or frequented by such person disinfected to the satisfaction of the port health officer.

11. Should any passenger be found to be suffering from plague or other infectiouis disease, such passenger, together with his or her relatives (that is, such relatives as have been living with or in dangerous communication with the infected case for any time within eleven days immediately preceding the discovery of the case at the medical examination), and non-medical attendants, are not permitted to embark, and their baggage and personal effects are not allowed on the vessel, and if already placed on board are removed as early as possible.

12. Should any member of the crew or passengers be found to be suffering from measles, scarlatina, cholera, small-pox, or leprosy in the alcerative stage, he is not allowed to embark, but is sent to a hospital for treatment, and a note giving particulars of each case should be made on Sanitary Form No. 18.

13. Whenever a case of plague is removed from a vessel, the 
vessel is thoroughly disinfected, and an endorsement stating what has been done is to be made upon the bill of health.

14. Passengers and members of the crew who may be slightly indisposed, or in whom there may be a slight rise of temperature, but who in the opinion of the inspecting medical officers do not show any symptoms which might give rise to the impression that they are suspicious cases, are to be handed over to the ship's master or surgeon for careful observation on the voyage and isolation, so far as it is possible, if the symptoms indicating it should arise.

15. The names of the members of the crew and passengers suffering from enlarged glands, but without any fever, are to be entered in the official log-book, and the matter brought to the notice of the commander and surgeon, so that in the event of their suffering from malarial or other fever at another port, the illness from which they are suffering may not be attributed to plague, and the vessel and those on board may not be subjected to unnecessary restrictive measures and detention. A list of such names is to be kept on the sanitary form sheet for the office records.

In the event of a commander objecting to a note being made in his log-book or other official document, the crew or passengers are to be prevented from embarking, in the interests of commerce and the travelling publie, on the vessel.

16. Passengers rejected may, if it is considered advisable by the inspecting medical officer, be sent to a hospital or place of observation appointed for the purpose. All the native crew rejected by the inspecting officers are to be sent to a hospital or the port health observation camp until after the vessel has sailed, so as to render it impossible for a rejected person to go on board again.

17. A police inspector is posted on the gangway of each departing vessel, who does not permit any person on board the vessel unless he is satisfied that such person must yisit the vessel in an official capacity, or is in possession of a pass from the port health department bearing the date of the day of the departure of the vessel.

The inspector collects the passes of such persons possessing them, and returns them without delay to the port health officer for check and record.

18. The senior medical officer present at any inspection is responsible for the thorough examination of the crew and passengers. He has to see that the vessel is in every way in a satisfactory sanitary condition, and that the bill of health is correctly filled in and handed to the Customs officer in charge of the vessel.

In the event of a vessel not being able to sail immediately after 
the inspection is completed, a European police constable is to be. left on board with instructions that no person is to be allowed to board or leave the ship, or cargo or packages to be taken to or from the vessel, except with the special written permission of one of the port health medical staff. If a vessel is in dock, she must be moved off the dock wall not less than 20 feet, and the gangway must also be removed, so that there can be no communication with the shore and the vessel. All local boats or other craft are to cast off prior to the commencement of the medical inspection. In the event of this rule being broken, the bill of health is to be brought on shore for disposal.

19. When the sanitary inspection sheet and form No. 18 are being filled in, the name of the medical officer who inspects any and each separate department of the orew or passengers has to be recorded.

The above rules constitute some of those in constant use governing ships, crews, and passengers on departure from Bombay. We will now turn to those which regulate the invard-bound shipping.

A member of the medical department of the port health staff is placed on constant "inward duty" (each in rotation) for one month at a time. Each incoming ship from an infected port is notified to the officer on duty by telegram from the Prongs Lighthouse. A form is sent (monthly) to the port officer informing him of the name and address of the medical officer on duty, and likewise of his deputy when the former is "off duty."

The medical officer boards the incoming vessel at the quarantine anchorage. He asks for the bills of health, and a report of the state of the health of the erew and passengers, and takes a signed declaration to this effect from the captain or surgeon, as the ease may be, in which is set forth the absence or otherwise of sickness or deaths during the voyage. The inspecting medical officer is also supplied by the commander or surgeon with a list of the passengers and the names of their ports of embarkation, together with the number of the entire crew.

He uses his discretion as to the necessity of a separate and individual examination of every European passenger, but invariably examines each person belonging to the third-class or deck passengers, together with the entire erew. In the case of a vessel on board which there is, or has been during the voyage, any case of plague, yellow fever, cholera, small-pox, scarlet fever, measles, or black leprosy, the medical officer examines the crew and all passengers, and makes a full inquiry into the circumstances attending the case or the cases of these diseases. Natives suffering from any one 
of these diseases are sent to the Arthur Road Infectious Diseases Hospital, Europeans to St. George's Hospital, and European and native troops to the military hospitals set aside for such cases by the military authorities. In the case of small-pox, the native crew and passengers are vaccinated, and vaccination on board the infected ships is offered to all before they are allowed to enter the town.

The clothes, bedding, and all personal effects of the passengers and crew on board the ship are disinfected before they are permitted to enter the town, the ship is as thoroughly disinfected as possible with solutions of mercuric chloride and carbolic acid 5 per cent. solution, and in the case of cholera the drinking-water is discharged into the sea, and the tanks are cleansed with potassium permanganate.

The vessel is meanwhile not allowed to have any communication with the shore or boats plying in the harbour until granted pratique by one of the port health staff. The greatest possible despatch, consistent with thoroughness, is used in the disinfection of the ship, passengers, and erew, in order that the granting of pratique may be delayed for the shortest possible time.

In addition to above diseases, there are also special regulations with reference to the importation of jigger, which is similarly dealt with.

The inspection of inward-bound passengers from local ports was commenced early in April, 1897, owing to the return of people from plague-stricken parts. This was done to protect Bombay from further re-infection from without; but when, owing to plague recurring in increasing and epidemic form, it was found useless to attempt to prevent its spread by any extraordinary port sanitary restrictive measures, the inspection was partly abandoned. However, whilst in force, the rules for such were found to be most efficient, and cannot be better described than in Colonel Macartie's own words :

"In dealing with the masses of people who eame under inspection during the four months April to July, 1898, on arrival from heavily infected places, such as Káráchi, Janjira, Alibág, etc., as well as from ports where plague had not reached epidemic proportions, although each case was decided on its own merits, it was found necessary to decide on some defined plan in order to eliminate the healthy from the suspected.

"A sliding scale of temperatures was accordingly introduced, and passengers were divided into classes according to their own state of health, and to the state of plague at the places which they were judged to have arrived from. 
"A map showing the progress of the disease, and altered according to the reports from the mofussil (country districts), was furnished by the Plague Committee, and in accordance with any alterations in this map the figures on the sliding scale of temperatures would vary."

Thus, arrivals from a place only slightly infected would, if free from other signs of plague, and with temperatures under $100^{\circ} \mathrm{F}$., be passed as healthy one week, and the next week, owing to unfavourable reports from the same place, would be placed in the observation camp if found with temperatures anything over normal:

This system was found to work well, and, as a brisk house-tohouse visitation was carried out by the Plague Committee at the same time, it is probable that few, if any, cases of plague which arrived by sea during the four months under report escaped detection, even if they succeeded in passing through the inspecting staffs in the harbour and at the bandars.

Some difficulty was experienced in discovering the places from which the passengers had really come. By arrangement the tickets were not collected until the inspection was over, and in many cases the tickets contained the information required. In other instances, however, the passengers had travelled on foot for many days, and covered long distances, in order to secure the cheaper transit by the Dharamter ferry-boat, the fare for which is by law fixed at 4 annas, and their original places of departure could with difficulty be traced, and in some instances not at all. When the process of elimination was completed, the "suspects" were transferred to the Plague Committee's observation camps, and detained there for periods varying from three to five and eight days, according as they had come originally from uninfected, moderately or heavily infected places. Actual plague cases were sent in ambulanees to a plague hospital.

Disinfection for Plague Purposes is carried out in the following manner (owing to the disinfection barge and store being but recently completed): All infected kit, bedding, curtains, carpets, etc., are stripped and taken out of the infected vessel and placed aboard lighters, and, together with the passenger and erew, brought ashore to the Malet Bandar or Modikhana disinfecting-stations.

Everyone is mustered in the disinfection-shed, a roll-call is taken, and each person, together with his belongings, is checked and compared with the ship's passenger-list and articles.

The crew are directed to wear shoes or boots when on shore, and to clean their feet before leaving and on returning to the ship.

Clothing and bedding are placed in a steam-disinfector, and each 
person is medically examined. Any elothing which is in the least degree soiled is passed through the sterilizer, and, if necessary, the entire wearing apparel is removed from the man, who is provided with clothes which have already been subjected to the steam at 10 pounds pressure and a temperature of $239^{\circ} \mathrm{F}$. for a quarter of an hour. Boxes and boots are placed in a large wooden vat containing mercuric chloride solution 1 in 1,000, and thoroughly scrubbed. The number of persons and articles presented for disinfection are recorded on a special form.

The medical officer in charge is required to see that the entire kit, clothes, bedding, and effects, together with all the boxes of the crew, are produced for inspection. This can be ascertained, as we have already shown, by calling a roll-call from the ship's articles or from a nominal roll furnished by the shipping officer or commander of the vessel. (We always insisted upon a nominal roll, because it is far more accurate than the ship's articles, which so far as native crews are concerned are often inaccurate.)

Directly the ship is reported to be free from all crew and passengers, a sanitary police officer is sent on board to examine the forecastle and ascertain whether it is free of all kit and bedding, and that kit has not been concealed in cupboards, lockers, forepeak, holds, stokeholds, or under the floors, etc.

After disinfection the kit is carefully removed to a separate part of the shed, where it is packed. It is afterwards conveyed on board under police escort. The ship is thoroughly washed down and cleansed prior to receiving the disinfected articles, and those of the crew who were compelled to stand by the ship during the absence of the others at the disinfection-shed are now brought ashore and similarly dealt with.

When the disinfection of the kit is finished the floors of the disinfection-shed are swept, the sweepings are burnt in the furnace, and the floor thoroughly watered with mercuric ehloride solution prior to dealing with another batch.

A complete record is kept of each disinfection upon a speciallyprepared form, together with aceurate notes of all men having enlarged glands and temperatures above the normal, and all names of such rejections or "suspects."

In the case of a vessel such as a P. and 0 . steamer bound for Europe or elsewhere, the crew will be medically examined at the shipping office and disinfeeted, careful notes being taken of all suspicious cases. The crew return to their ship under police escort, and are allowed to have no communication whatsoever with the shore. They are again most carefully examined, probably by a 
different set of observers, who have the disinfection form, together with the disinfection officer's remarks, before them, just before the vessel is leaving her anchorage in the stream. If during the two or three days which have elapsed since disinfection took place the symptoms already noted at the disinfection-shed become in any instance more pronounced, the patient is rejected and sent to hospital for further observation. Sometimes there is even a fourth medical examination of the crew, and in the case of any doubt arising redisinfection is always resorted to.

\section{The Method of conducting the Medical Examination of Crew and Passengers.}

Prior to 1899 the port health officer's medical staff worked in conjunction with the Customs medical staff, but this was abandoned in January, 1899.

The administrative staff of the port health officer (Major Crimmin, V.C., I.M.S.) consists of six European assistant port health officers, six assistant surgeons, six hospital assistants, and three lady doctors. Each officer receives every evening at 9 p.m. a programme of the work he has to do on the following day, together with the hour and place in the docks, disinfection-shed, bandar or stream at which the vessels are lying. By the terms of the Venice Convention, the examination may not commence earlier than sunrise nor continue later than sunset.

The routine is as follows :

The passengers are assembled in long sheds (facing the dock wall and the outgoing vessels), which are divided into two main divisions for male and female deck passengers, with smaller enclosures for first-class passengers and "suspects" or rejected passengers and crew.

The people having been arranged in lines along the shed (about 100 in each batch), each person is requested to raise his arms above his head, and the medical officer explores the axillæ, groins, and neck for glandular enlargement or tenderness. He then examines the tongue and conjunctiva, and tests the body temperature by placing the palms of the hands against the skin of the thorax, checking this test against the surface temperature (tested in the same way) of the examinee's next neighbours on each side of him. If there be any glandular enlargement or the slightest suspicion of inereased body temperature, the patient is at once set aside for further examination, his (thermometrical) temperature is taken by a hospital assistant, who registers the actnal observation 
upon a slip of paper, and presents it, with the patient, to the senior port health officer present at the inspection. The latter carefully investigates the case by physical examination and verbal inquiries, and decides as to the suitability or otherwise of the passenger's fitness to travel. If he decides that the patient may travel, a special signed and stamped pass is given to him, stating what has been discovered at the examination and the reasons why he has been permitted to pass. This pass is made in duplicate, one copy being given to the passenger, who has to produce it to the authorities on reaching his destination, and the other, containing the notes of his case, being retained for reference by the port health office.

If the circumstances warrant the patient's detention, the following steps are taken :

(a) If the case be one of plague or other dangerous infectious disease, the patient is at once removed to hospital in an ambulance.

(b) If a suspicious case, he is sent to the port health observation camp.

(c) If suffering from slight but doubtful symptoms, as, for instance, mere painless glandular enlargement, he is permitted to remain at home under surveillance, and on subsequently presenting himself for examination is, if otherwise healthy, allowed to proceed on his journey.

Women and children are dealt with in exactly a similar manner by the lady doctors, who are directly responsible to the port health officer or, in his absence, the senior health officer at the shed.

Europeans and natives are treated upon the same principles, the only difference being that they are examined in different enclosures of the same shed. The Parsees and Brahmins occasionally give a little trouble, but this is not frequently the case. The people, as a whole, have now recognised the main fact, namely, that we have no desire to put them to any further inconvenience than is absolutely necessary for their protection. Others, who do not care one way or the other, have become so accustomed to the procedure that they look upon it as the usual routine of travel; and so long as they are permitted to "baitho" (i.e., to squat or sit down), they appear quite contented.

The foregoing is a brief deseription of the medical examination which takes place all day. long for every ship about to leave the docks, together with those in the stream, which, in addition, have to be re-examined and checked by means of the disinfection returns furnished, as already stated, by the officer on duty at the disinfection-station. 
At this time, also, all boxes and baggage are checked, each being examined for the official stamp mark of the disinfection-station, and then numbered with chalk and a tally made, which must coincide with the returns alluded to. Any box not bearing the official date and mark is, together with its owner, forthwith removed from the ship, and prevented from sailing.

Appended is a tabular statement of the actual amount of shipping and the number of passengers dealt with during the year 1899 , which was prepared by Major Crimmin for his annual report for 1899.

THE PORT OF BOMBAY.

\section{A Summary of the Shipping, Infectious Disease and Work} connected therewith for 1899.

\begin{tabular}{|c|c|c|c|c|c|c|}
\hline $\begin{array}{l}\text { Vessels, indusive o } \\
\text { Country Craft. }\end{array}$ & $\begin{array}{c}\text { No. of } \\
\text { Vessels } \\
\text { inspected. }\end{array}$ & $\begin{array}{l}\text { No. of } \\
\text { Persons in- } \\
\text { spected, } \\
\text { including } \\
\text { Crews. }\end{array}$ & $\begin{array}{c}\text { No. of } \\
\text { Passengers } \\
\text { and Crew } \\
\text { disinfected } \\
\text { Fob. 14th } \\
\text { to } \\
\text { Dec. 31st. }\end{array}$ & $\begin{array}{l}\text { No. of } \\
\text { Vessels dis- } \\
\text { infected. }\end{array}$ & $\begin{array}{c}\text { No. of } \\
\text { Persons } \\
\text { vacoiuated. }\end{array}$ & $\begin{array}{l}\text { No. of } \\
\text { Persons } \\
\text { segregated } \\
\text { or } \\
\text { rejected. }\end{array}$ \\
\hline $\begin{array}{ll}\text { Inward } & \ldots \\
\text { Outward } \ldots & \ldots \\
\text { In harbour during } \\
\text { the year }\end{array}$ & $\begin{array}{r}1,198 \\
64,594 \\
30\end{array}$ & $\begin{array}{r}76,910 \\
1,116,429 \\
-\end{array}$ & $\begin{array}{r}3,485 \\
44,864 \\
-\end{array}$ & $\frac{32}{30}$ & $\begin{array}{l}32 \\
-\end{array}$ & $\begin{array}{r}238 \\
17,424 \\
-\end{array}$ \\
\hline Total... & 65,822 & $1,198,389$ & 48,349 & 62 & 32 & 17,662 \\
\hline 1898 & 71,498 & $1,207,571$ & - & 49 & 150 & 19,138 \\
\hline
\end{tabular}

Infectious Diseases and Number of each.

\begin{tabular}{|c|c|c|c|c|c|c|c|c|}
\hline $\begin{array}{l}\text { Vessels, inciusive of } \\
\text { Country Craft. }\end{array}$ & Plague. & Cholera. & Variola & Measles. & $\begin{array}{l}\text { Scarlet } \\
\text { Fever. }\end{array}$ & $\begin{array}{l}\text { Vari* } \\
\text { cella. }\end{array}$ & Jigger. & Totals. \\
\hline Inward & 4 & - & 1 & 2 & 5 & 7 & 168 & 187 \\
\hline $\begin{array}{l}\text { Outward } \ldots \\
\text { In harbour during }\end{array}$ & 117 & - & - & - & - & 一 & - & 117 \\
\hline the year... & 34 & 1 & 1 & 5 & - & - & - & 41 \\
\hline Total ... & 155 & 1 & 2 & 7 & 5 & 7 & 168 & 345 \\
\hline 1898 & 118 & 5 & 6 & 4 & 3 & 10 & - & - \\
\hline
\end{tabular}

It will be seen that 65,822 vessels of all sorts, carrying $1,193,339$ passengers and crew, were examined during the year. These numbers include every person who left Bombay by sea during the year, as well as those who arrived from certain infected ports. The bedding, ete., of 44,864 native crew, third-class, and deck passengers who sailed on vessels for ports out of India were disinfected during that period, and the baggage of 862 returning pilgrims and 2,623 deck passengers who arrived from East African (jigger-infected) 
ports was disinfected. The total number of plague cases detected during the year 1899 was 155 , as against 118 for the year 1898 . These figures afford some idea of the amount of work which has to be got through.

The native craft, prows, bungalows, and muchwas (fishing-boats) also entail much attention, especially with reference to the export of cholera and small-pox, as well as plague. Each is medically examined prior to its departure, viz., the crew, bilges, passengers, water-supply, and vessels, together with passes and papers having reference to the "shore inspection" and disinfection. If found to be satisfactory, a bill of health is granted; if the contrary, the vessel has to remain at its anchorage until all the regulations of the port are complied with in full.

Special moorings are set apart for these vessels at free and dutiable anchorages in order that they may not mingle with, or be in the way of, the larger vessels.

Every commander, native captain, or agent, prior to sailing from the Port of Bombay, has to notify such intention to the port health officer as well as the Customs department.

The forms which are used by the office are appended, together with others, inclusive of some of the returns made by the health officer to the Government.

\section{Hospitals and Observation Camps.}

All cases of dangerous infectious disease found at the inspections held ashore or afloat are immediately sent in ambulances to one or other of the special plague hospitals or to the Arthur Road Infectious Disease Hospital, all of which are under the direct control of Colonel Wilkins, D.S.O., the medical adviser to the Plague Commissioner. Many of the hospitals are temporary structures allocated to the several religious castes, and well suited to the purpose. Others are permanent structures similar in many respects to our own isolation hospitals.

So far as the port is concerned, it has the sole administration of its own port observation camp, which is situated upon an open space facing the harbour, and adjoining the Modikhana Hospital. It consists of one large central circular ward constructed of matting and bamboo, roofed with a thatch of palm-leaves, and six other wards and offices, the whole capable of accommodating about 80 to 100 persons.

These structures are all similar in construction, and are entirely enclosed within a fenced compound, which is guarded by native police, and administered by European assistant port health officers 
under the immediate control of Major Crimmin, V.C., I.M.S. The subordinates are:

1. A native medical practitioner, who resides within the hospital, and acts under the guidance of the European officer referred to, who visits the camp once or twice daily.

2. An ayah, who supervises the wards set apart for females and children.

3. Police, sweepers, coolies, and a peon.

All "suspects" who have been rejected at the medical inspections on the bandars or from ships in the stream are noted in a special book, and the counterfoil, signed by an assistant port health officer, and containing the names and symptoms (including the surface or skin temperature at the time of the medical inspection), is given to a European police-constable, who is responsible for the safe conduct of these people to the observation camp. No person can be received or discharged from this camp without a pass countersigned by the European assistant port health officer, for the time being, in charge of the camp.

On their arrival at the camp, the "suspects" are admitted by the native assistant surgeon, who enters their names, castes, and addresses, together with their temperatures, on examination at the inspection, and also at the time of admission, together with any symptoms of disease they may present.

Apart from the name of the patient, for further identification, any peculiar mark or deformity is noted on the temperature-chart which each person receives on admission. If subsequently he develops plague or any other infectious disease, he is forthwith transferred to a plague hospital or other isolation hospital, and a report giving full particulars of the case is forwarded by the assistant port health officer in charge to the port health officer, who in turn reports to the Bombay Government.

As plague not infrequently appears in patients having a temperature of under $100^{\circ} \mathrm{F}$., every case is judged entirely upon those symptoms which are present as a whole, and not upon any one particular symptom. In cases where after two or three days the temperature has fallen to the normal, and no other symptoms of plague or other infectious diseases are present, the "suspect" may be discharged altogether, or, if still a suspicious case, upon a "surveillance certificate," provided that a justice of the peace or other person of position will guarantee that the holder of the certificate will present himself for examination daily at the camp. The poor are fed, and special arrangements are made with regard to the separation of castes. There can be little doubt this pre- 
cautionary segregation is the one measure which, in the Port of Bombay, is most objected to by the natives, although, so far as it is possible, they are made comfortable during their enforced isolation. It is for this reason that most of the "suspects" are now allowed to return to their homes in the city. It is also the most difficul's measure to carry out efficiently, and yet there can be no doubt that, when it can be done, it is a valuable means for the prevention of the spread of disease.

The great difficulty to be content:ad with in India is the corrupt character of all the native overseers. Bribery with them is a custom so deeply engrafted into their character that its eradication is most difficult. We have had on several occasions to complain, and even to prosecute the native police for their corruptibility and persecution of the people placed under their eharge. Many of the native police, moreover, appeared to be almost devoid of the least feeling of humanity towards their fellows.

\section{Other Santrary and Inspectoriat Duties.}

Periodical surveys are made of the shipping in the port, both European and native, including the sanitary condition of the sheds, bandars, and sanitary appliances and water-supplies.

Police patrols are regularly carried out by the sanitary (European) police to prevent evasion (by the native sailing craft and others) of the rules as regards the carriage of passengers between Bombay and other ports, etc. Every now and then these delinquents are caught and summarily dealt with by the magistrates (some of the offenders getiting as much as a month's imprisonment).

A complete survey was recently made in order to collect the exact details and measurements of the sleeping quarters on steamers trading with Bombay. This report was called for by the Government with reference to the sufficiency or otherwise of the air-space supplied to the lascars, and its relation to the diseases prevalent amongst them.

Careful measurements were made of all parts of the ships occupied by native seamen, together with the means adopted to ventilate them; their structural defects, such as their partial occupation by winch-engines, cables, etc.; direct or indirect communication with latrines and holds; the nature of the lining, whether in wood or iron; and the painting, cleanliness, or dampness of the crew's quarters. The medical diaries and logs of ships, together with the records of the shipping offices, were searched to ascertain the amoun and character of any diseases prevalent amongst lasears. 
These investigations convinced us that the amount of cubic airspace, viz., 6 superficial feet and 36 cubic feet (half that allotted to British seamen), was most insufficient.

Respiratory diseases (including pneumonia and phthisis) are too prevalent amongst these men, owing possibly to the fallacious opinion which prevails in shipping quarters that these native seamen do not require more shelter. It is thought that, as the men are in the tropics, they can sleep on deck; but no account is taken of the facts that exposure at night anc. during the day, whilst the monsoon prevails, and the changes of latitude which most of these oceangoing steamers make, subject these men to the severest changes of temperature and to inclement weather, to which they are less accustomed than the British seamen. Even the limited air-space which is now enforced is still further curtailed by the crew's kit and boxes. Although we have tried to prevail upon the lascar to use canvas bags (which are in every way more convenient for stowage, disinfection, and cleansing than boxes), yet he prefers his box, with its indifferent lock, its cockroaches, and vermin, to the naval seamen's hold-all, and will not discard it if possible.

We have to add with regret that the cleanliness of the cabin quarters and the bodies of many European crews compare most unfavourably with those of lascars or Chinamen.

In conclusion, we would again quote from the report of the Port Health Officer of Bombay for the year 1899, who says :

"Unfortunately, plague has broken out at foreign ports ; but so far no country or port can point to Bombay as being the source of the plague from which they are suffering; at least, in no case can outbreaks in foreign ports be traced to the crew or passengers from Bombay. The question of infection by rats and cargo has not been touched upon, as presumably the subject will be fully dealt with in the report of the Indian Plague Commission.

"The majority of plague cases in the East contract the disease by inoculation through wounds, cracks or fissures, and ulcers on the feet, as the large majority of the people go barefooted.

"It is therefore probable that, so long as the plague in the East is confined to the bubonic type, the people at European ports, and other ports where the population wear boots or shoes, will not suffer from this disease in an epidemic form."

Since the report quoted above was published, the Indian Plague Commission have issued their report, and, with reference to the matter of infected cargo or rats as a means of transmission of plague, they say:

"Experiments in laboratory and practical experience alike tend 
to show that little danger is to be apprehended of the spread of plague by ordinary articles of merchandise."

The Commission point out that it would not, in the case of any variety of merchandise, be practicable to employ any method of disinfection certain to bring about immediate destruction of any plague bacilli which might chance to have been introduced into the material, and that the only possible precaution which could be taken against the accidental conveyance of infection by merchandise would be to insist that it should be received for transport only when thoroughly dry. Security for this is already in large measure afforded by commercial economic reasons, inasmuch as merchandise would, if shipped damp, inevitably undergo deterioration in transit.

In view of these considerations, the Commission are of the opinion that it is neither advisable nor necessary to take any steps towards the disinfection of ordinary merchandise.

Secondly, with reference to the transmission of plague by means of infected rats, the Commissioners state that, although theoretically it is possible that plague-infected rats might carry the disease from one country to another, there is no evidence that infection has ever been carried in this manner. They think that the suggested fumigation of the holds of ships so as to destroy the rats is both unnecessary and impracticable.

\section{DISCUSSION.}

Dr. AxLAN, after testifying to the interest which the reading of the paper had aroused, asked whether the authors' experience bore out the allegation that different species of rats were in varying degrees susceptible to plague infection, and whether there were any data as to the length of time the virus could remain active in rags. He also drew attention to the difficulty expexienced in this country in tracing persons reported by Port Sanitary Officers to have gone to a certain address, frequently no such person being found at the address in question.

Dr. Farrar, who had been in the Bombay district on plague duty, said the native was easy to deal with if his susceptibilities as to his food and his women were considered; he did not mind any amount of detention, as time was of no value to him. He was sure Dr. Adarns did not intend to convey the impression that he did not regard the preceding mortality of rats as important. He thought that they did not so much direetly convey infection as that they infected the soil, especially the earth-floors of the houses, on to which all kinds of filth fell. The reason why former epidemics of plague had been shorter than the recent one was that formerly an infected town or village would be evacuated by the population, who would migrate elsewhere, whereas now the civilization introduced by our. selves tended to keep them in the infected houses. The people sat and lay on these foul earth-floors scantily clothed and with bare hands and feet, and then became infected through any chance abrasions. In the Middle Ages floors of houses in this country were not unlike, with their covering of loose, often foul, rushes, and so plagne spread in the same way. He thought, therefore, that 
though there might be cases imported, there was no danger of a plague epidemic occurring now in this country.

Dr. ADAMs, in reply, said they always laid stress in Bombay on the danger of infected clothing. Rats were a danger, but not the greatest danger. Dr. Parelle, of the Pasteur Institute, found that all the species of rats were equally susceptible to plague. Clothing, however, he believed to be the usual method in which the disease was introduced, and he instanced the occurrence at the Cape, in the Suez Canal, and at Mecca. Clothing could retain infection for a long time, and in one case where clothing had been on board for five weeks an outbreak was cansed by its unpacking. Fleas also, he thought, spread the disease. In Bombay they had two seasons of greatest prevalence of plague-one, the greatest, in December and January, when the cold weather made the natives live in the houses, which became much overcrowded; and the second, not so great as the first, a fortnight after the monsoon broke, when the wet again led to overerowding. Most of the rooms were very dark and ill-ventilated, and favoured the growth of the bacillus, which Dr. Parelle had shown throve in an atmosphere rich in earbonie acid. Sunlight was a most important destroying agent. In almost all cases of plague an abrasion, which was the seat of inoculation, could be found, and it was often under the toe-ring worn by most of the natives.

A vote of thanks was tendered to Dr. Adams for his paper.

APPENDIX: FORMS USED, ETC.

BOMBAY:

\author{
Peningular and Origintal Steam Navigation Company, \\ March 16th, 1900.
}

Important Notice.

The attention of HOMEWARD passengers is directed to the necessity, under the provisions of the. Venice Convention, of undergoing a medical examination by the health officer of the port on shore prior to embarkation. This inspection in the case of the homeward mail steamers will take place at the Ballard Pier between 11 a.m. and 12.30 p.m. on the day of sailing (Saturday). The Company's tenders will leave the pier at intervals, and no one will, under any circumstances, be allowed on board the mail steamer unless they proceed in these tenders, and are in possession of the permit given by the health officer at the time of examination, which permit must be produced on board.

After such medical examination passengers will not be permitted to have any direct communication with the shore, and no friends or attendants can be allowed to go on board the mail steamer. A steward and stewardess attend on board the tenders to render assistance to invalids and children during the passage to the steamer.

Heavy baggage must be sent to the Ballard Pier on Friday afternoon, the day previous to sailing, and cabin baggage before $9 \mathrm{a.m}$. on Saturday. The attention of passengers is ealled to the importance of having their baggage labelled with port of destination.

F. Piтchie, Superintendent. 


\title{
NOTICE FOR VESSELS LEAVING BOMBAY FOR INDIAN PORTS.
}

\author{
Forwarded throvgh Messrs. \\ AGENTS OF THE S.S. ............... \\ From \\ To \\ The Health Officer of the Port of Bombay, \\ The Commander, s.s. \\ Bombay Pont Heamth Office, \\ Town Customs House, \\ Dated .............., 190 .
}

Sre, -I have the honour, by direction of the port health officer, to inform you that some of the officers of the port health staff shall board your vessel, s.s. .............., in the about the instant and issue a bill of health, provided that the Captain, all offeers and members of erew are on board at the time of their inspection; and that the vessel is in a satisfactory sanitary condition, especially in the foreastle and bilges, which must be absolutely clean.

2. All passengers should be inspected on shore prior to embarkation, and no passenger should be allowed on board unless he or she is in possession of a pass from one of the port health staff.

3. Should there be any newly shipped member from Bombay among the crew, he should be sent to Modi Bandar (Shepherd's Wharf) for medical inspection on shore prior to his embarkation, and he should obtain a pass from the inspecting medical officer to that effect.

4. Native crew's boxes or bags should be open and on deck. The forecastle, whether European or native (which should be thoroughly cleaned and limewashed, or freshly painted or disinfected with a 5 per cent. solution of carbolic acid, or a solution of 1 in 1,000 of perchloride of mercury), should not contain any bedding, clothing or any other belongings of the erew at the time of inspection. Vessels in ballast should have their holds absolutely clean. Owing to the tendency of coolies employed in the dischirge of coal and other cargo to use any convenient corner as a latrine, special attention should be paid to the cleansing and disinfection of the holds of vessels.

5. Visitors should be asked to leave the vessel before the time fixed for inspection.

6. The Commander should note that when the inspection is over no passenger or member of the crew is permitted to leave the vessel whilst in this port. Nor are natives or other persons from shore to be allowed on board without the permission of the port health officer.

7. The articles should be correct and show the names of all the orew.

8. The vessel should arrange to move off from the dock wall so that no person may be able to go on board nor leave the vessel after medical inspection.

9. All work and papers should be completed before the time fixed for the inspection of the vessel.

10. No bill of health will be issued unless these rules are carried out to the letter.

I have the honour to be, Sir, Your most obedient servant, 
N.B.-According to Government instructions the bill of health must be given on the date of sailing.

Ships postponing their departure and not giving due notice of such to the health officer are liable to suffer inconvenience, more especially during the busy season, as the health officer may not be able to reinspect them at an hour to suit the Commander.

\title{
DISINFECTION OF THE NATIVE CREW.
}

From

To

\author{
The Health Officer of the Port, Bombay,
}

The Commander, s.s.

\section{Bombay Pont Heaxth Office, Town Customs House, Dated ................, 190 .}

Sir,-I am directed to inform you that the clothes and bedding (either crew's or ship's property) of the Asiatic and African members of the orew, including those in the saloon, of the s.s. .............. will be disinfected at the Port Health Disinfecting Station at Malet Bandar at the

instant, and to request that you will kindly arrange to have all the members of the native crew, including Eurasians, with their effects and boxes, ready at that time. An offeer should accompany them and bring a nominal roll of the crew with him.

If any of the native crew's clothes, bedding, or boxes are left on board, or are sent on board without being disinfected, a bill of health will not be granted to the vessel.

I have the honour to be, Sir,

Your most obedient servant,

Head Clerk to the Health Officer of the Port.

Forwarded through the agents

\section{DISINFECTION OF THE DECK PASSENGERS.}

From

To

The Health Officer of the Port, Bonbay,

The Coymander, s.s.

\section{Bombay Port Heatith Office, Town Customs House, Dated ................, 189 .}

$\mathrm{SrR}_{3}$ - I am directed to inform you that the clothing, bedding, and effects of the third-class or deck passengers and Asiatic or African servants or passengers sailing in the s.s. will be disinfected at the Port Health Disinfecting Station at Malet Bandar at the instant, and to request that you will kindly arrange to have all such passengers and servants with their property ready at that time. Some responsible person should 
accompany them and bring a nominal roll of the passengers whose kit has to be disinfected. If any of the above passengers' clothes, bedding, or boxes are allowed on board without being disinfected, a bill of health will not be granted to the vessel.

I have the honour to be, Sir,

Your most obedient servant,

Head Clerk to the Health Officer of the Port.

Forwarded through the agents

(A) FOR INDIAN PORT.

BILL OF HEALTH.

This is to certify that the ship (steamer) sailing under the flag, and under the command of Captain of .... tons, bound for with a crew of passengers, and laden with a cargo and able-bodied seamen) and of ..............., is at the time of leaving this port in a satisfactory sanitary condition, and that no ease of infectious disease dangerous to life exists among its officers, passengers, or crew. The passengers have been examined by day on shore before embarkation, and found free from plague.

It is further certified that the town and port of Bombay are at present free from epidemic yellow fever, and all other dangerous epidemic disease, except plague and cholera, which exist in an epidemic form.

Health Officer of the Port, Bombay.

\title{
NOTICE.
}

\author{
Bombay Port Heacth Offich, \\ Town Customs House, \\ Dated ..............., 190 .
}

Commanders of vessels leaving Bombay at a time when plague is prevalent are recommended to see that the elothing and kit of all native crew and native passengers are exposed to air and sun on as many occasions as possible during the voyage.

It is also recommended that the boxes of the native crew be frequently opened and thoroughly cleaned inside.

Health Officer of the Port.

(B) FOR VESSEL LEAVING FOR PORTS OUT OF INDIA.

\section{BILI OF HEALTH.}

This is to certify that the ship (steamer) .............., sailing under the flag, and under the command of Captain

tons, bound for ..............., with a crew of .............. persons (including officers and able-bodied seamen) and .............. passengers, and laden with a cargo 
of .............., is at the time of leaving this port in a satisfactory sanitary condition, and that no case of infectious disease dangerous to life exists among its officers, passengers, or crew, who have been examined by day on shore before embarkation, and found free from plague.

It is further certified that the town and port of Bombay are at present free from epidemic yellow fever, and all other dangerous epidemic disease, except plague and cholera, which exist in an epidemic form.

The clothing and bedding of the native crew, and of the third class or deck passengers, have been disinfected on shore.

Health Officer of the Port, Bombay.

\section{CERTIFICATE.}

Bombay Port Healith Offick, Town Customs House, Dated ................, 190 .

This is to eertify that during the last week previous to the departure of the ship (s.s.) ............... from this place there occurred in the town and port of Bombay-

deaths from plague,

............... death from from chollow fever,

declared by the Medical Board to exist in an epidemic form, and that the public health of the environs is poor, owing to the existence of cholera and plague in an epidemic form.

Health Offieer of the Port, Bombay.

NOTICE FOR VESSELS LEAVING BOMBAY FOR PORTS OUT OF INDIA.

Foritarded THRotgh Messrs.

AGENTS OF THE S.S.

From

The Heafter Officer of the Port of Bombay,

To

The Commander, s.s.

Bombay Port Health Office, Town Customs House, Dated ................, 190 .

SrR, - I have the honour, by direction of the port health officer, to inform you that some of the officers of the port health staff will examine the Captain, all officers and members of the crew of your vessel, s.s. .............., in the at on the instant, and the passengers in the .............. at .............. the ............. instant, and that an officer of the the .............. at .............. the ............. instant, and that an officer of the the ............. at .............. the ............. instant, and that an officer of the factory sanitary condition (especially the forecastle, decks, live stock, pens and bilges, which must be absolutely olean), and that every person about to sail in the vessel shall have passed a medical examination upon shore, and is on board. at the time of his visit. 
2. The articles should be correct, and show the names of all the crew.

3. Native crews' boxes or bags should be open and on deek, and the forecastle (which should be thoroughly cleaned and limewashed, or freshly painted or disinfected with a 5 per cent. solution of carbolic acid or a solution of 1 in 1,000 of perchloride of mercury) should not contain any kit at the time of inspection. Vessels in ballast should have their holds absolutely clean. Owing to the tendency of coolies employed in the discharge of coal and other cargo to use any convenient comer as a latrine, special attention should be paid to the cleansing and disinfection of the holds of vessels.

4. Commanders should note that when the inspection is over no passenger or member of the crew is permitted to leave the vessel whilst in this port, nor are natives or other persons from shore to be allowed on board without the permission of the port health officer.

5. Commanders should also note that after the hour fixed for the shore inspection no person or persons shall be present on board who is or are not passengexs or present in some official eapacity, or in the possession of a permit from the health officer of the port.

6. No bill of health will be issued unless these mules are carried out to the letter.

I have the honour to be, Sir,

Your most obedient servant,

\section{Head Clerk to the Health Officer of the Port.}

N.B.-According to Government instructions the bill of health must be given on the date of sailing.

Ships postponing their departure and not giving due notice of such to the health offecer are liable to suffer inconvenience, more especially during the busy season, as the health officer may not be able to reinspect them at an hour to suit the Commander.

\section{VENICE SANITARY CONVENTION OF 1897.}

\section{Chapter $\mathbf{V}$.}

Precautionary Measures recommended for Shtps on Departure, during the Voyage, aNd on Arrival.

Note.-Plague appears to be transmitted by the excretions of the sick (from the air-passages and bowels), by the morbid products of the disease (pus), and consequentily by means of linen, elothing, and soiled hands.

\section{Measures to be taken on Departure.}

1. The captain should be careful not to embark persons suspected to be suffering from plague. He should refuse to receive on board dirty or suspicious linen, personal effects, and bedding, and, generally, all dirty or suspicious articles.

Bedding, wearing apparel, personal effects, etc., belonging to persons suffering from plague should not be taken on board.

2. Before embarkation the ship should be put in a state of perfect cleanliness, and she should, if necessary, be disinfected.

3. It is essential that the drinking-water taken on board should be obtained from a source free from all possible contamination.

Water is not dangerous if it is distilled or boiled. 


\section{Measures to be taken during the Voyage.}

1. Every ship should have a special place reserved for the segregation of persons attacked by contagious disease.

2. If there is no such place on board, the cabin or other place in which a person is attacked with plague should be isolated.

Only those attending the patients should be admitted.

Such attendants should be cut off from all contact with the other persons on board.

3. The bedding, linen, and clothing which have been in contact with the patient should immediately, and in the patients' room, be soaked in a disinfecting solution.

The same measure should be taken in the case of the clothing of the persons who have access to the patient which may have become polluted.

Articles which are of no value should be burnt, or thrown overboard, if the ship is not in port or in a canal. Other articles should be carried to the stove, in impermeable bags, sprinkled with a solution of corrosive sublimate, so as to avoid all contact with surrounding objects.

If there is not a stove on board, the articles should be soaked in the disinfecting solution for six hours.

The excreta of the siek should be collected in vessels, into which a glass of the disinfecting solution above described has been previously poured.

The vessels should be at once emptied into the latrines, which should be disinfected each time.

4. The places occupied by the sick should be carefully disinfected according to the rules previously laid down.

5. Corpses should be wrapped in a shroud impregnated with corrosive sublimate and thrown into the sea.

6. All the preventive measures taken during the voyage should be stated in the $\log$, which should be submitted to the sanitary authority immediately on arrival in port.

7. The measures should be applied to everything that has been in contact with the sick, irrespective of the gravity and result of the illness.

Disinfectant Properties of Alcomol. - The conclusions arrived at by Epstein and others concerning the value of alcohol as a disinfectant have been corroborated by Bertarelli (Il Policlinico, 1900, through Revue d'Hygiene, January, 1901), who experimented with silk threads, infected with fresh and old cultures of $B$. prodigiosus, $B$. pyocyaneus, $B$. pestis, B. cholera, B. typhosus, Staphylococcus pyogenes aureus, and sporulating $B$. anthracis and $B$. subtitis, which were exposed at different temperatures and for periods ranging from five minutes to fifty days. The best results were obtained with alcohol of 50 per cent. strength, the power diminishing with departures in both directions from this dilution. Thus, 70 per cent. strength was more powerful than 25 per cent. strength, and both than 88 and 99 per cent. The action of any dilution on spores was practically nothing. Alcoholic solutions of corrosive sublimate $(1: 1,000)$, carbolic acid ( 3 per cent.), chromic acid ( 1 per cent.), silver nitrate ( 0.40 per cent.), and zinc sulphocarbolate (2 per cent.), were more active the less the alcoholic strength.-Amer. Jour. Med. Sci. 